\title{
Valor nutritivo da leguminosa Pueraria phaseoloides como alternativa na suplementação alimentar de ruminantes na Amazônia Oriental
}

\author{
Nutritive value of the leguminous Pueraria phaseoloides as an alternative of \\ alimentary supplementation of ruminants in Eastern Amazon \\ Edwana Mara Moreira Monteiro ${ }^{*}$ José de Brito Lourenço Júnior ${ }^{\text {II }}$ \\ Núbia de Fátima Alves dos Santos ${ }^{\text {II }}$ Márcia Alessandra Brito de Aviz ${ }^{\text {II }}$
}

\section{- REVISÃO BIBLIOGRÁFICA -}

\section{RESUMO}

A pecuária é uma atividade de índices produtivos satisfatórios na região amazônica. Entretanto, alguns ruminantes são mantidos, na sua maioria, em pastagens implantadas em solos de baixa fertilidade, sujeitas a estresses climáticos, com reflexos negativos na disponibilidade e valor nutritivo da forragem produzida. Nesse aspecto, inovações tecnológicas adequadas à região, contribuirão para elevação dos padrões produtivos, através da intensificação no uso de suplementação alimentar, com leguminosas adaptadas. A leguminosa Pueraria phaseoloides apresenta diversas vantagens como cultura intercalar, destacando-se: melhor conservação do solo, alta produção de massa verde, alta concentração de proteínas nas suas folhas, dentre outras. Assim, essa leguminosa desponta como alternativa na suplementação alimentar de ruminantes, devido ao seu potencial forrageiro.

Palavras-chave: composição química, consumo, digestibilidade, forragem, proteína bruta.

\section{ABSTRACT}

The animal production is a satisfactory index activity in the Amazon region. Ruminants are mainly kept on pastures cultivated, in soil of low fertility, submited to climatic stresses, with negative consequences on the availability and nutritional value of forage produced. In this aspect, technological innovations adjusted to the region will contribute to rise the productive standards of the cattle, by the intensification in the use of feed supplementation, with adapted leguminous. The Pueraria phaseoloides leguminous presents many advantages as a culture to intercalate, being distinguished as having better conservation of the ground, high production of green mass, high protein content of the leaf and other advantages. Thus, 'pueraria' is as an alternative for feed supplementation of ruminants, due to its forage potential.
Key words: chemical composition, crude protein, digestibility, forage, intake.

\section{INTRODUÇÃO}

A pecuária da Amazônia tem sido o agronegócio mais estável das últimas quatro décadas e está alicerçada na variabilidade genética dos animais e forrageiras, nas satisfatórias condições edafoclimátcas e na demanda crescente dos mercados interno e externo. Detém um rebanho de 26 milhões de cabeças, gera produção anual de 1 bilhão de reais, é responsável por $80 \%$ do agronegócio regional e emprega, diretamente, $14 \%$ da força de trabalho rural na cadeia produtiva, o que gera empregos nos segmentos pré e pós-fazenda e ocupa $80 \%$ da área utilizada na região (MOURA CARVALHO et al., 2003; LOURENÇO JUNIOR et al., 2005).

Na Amazônia Oriental, o período de estiagem provoca escassez de forragens e redução de sua qualidade nutricional, com efeitos negativos na produtividade e competitividade no setor agropecuário. A produção de suplementos de baixo custo, dentre os quais se destacam as leguminosas arbustivas adaptadas à região, constitui grande passo para o desenvolvimento dos sistemas de produção animal. Dependendo do tipo climático, a pecuária sofre a deficiência de alguns nutrientes nos sistemas que têm como base o uso de pastagens, sendo necessária a

\footnotetext{
'Programa de Pós-graduação em Ciências Agrárias, Universidade Federal Rural da Amazônia (UFRA), Belém, PA, Brasil. E-mail: edmara6@yahoo.com.br.*Autor para correspondência.

"Programas de Pós-graduação em Ciências Agrárias, UFRA. Programa de Pós-graduação em Ciência Animal, Universidade Federal do Pará (UFPA). Belém, PA, Brasil.
} 
suplementação alimentar, visando a um melhor desempenho animal (CASTRO, 2005).

Um desafio constante é predizer o impacto da suplementação no desempenho animal e a estratégia adequada para elevar o consumo e a digestibilidade da forragem disponível. As leguminosas forrageiras arbustivas possuem esse potencial, particularmente em zonas do trópico úmido, produzindo mais biomassa que as herbáceas, sendo mais tolerantes, além de possuírem capacidade de rebrota e oferta de forragem de boa qualidade durante o ano inteiro.

\section{Pecuária na Amazônia}

A pecuária na região amazônica é uma das principais atividades que sustentam o desenvolvimento da economia regional, apesar de promover importante conversão de florestas em pastagens. A quantidade de floresta tropical natural nessa região tem diminuído drasticamente nas últimas três décadas. Nesse período, a área desmatada passou de 4\%, nos fins dos anos 70, para 15\% em 2001. Desse total, no final dos anos 90, aproximadamente, $70 \%$ da área foram destinados para a formação de pastagens cultivadas. Os fatores que afetam o desmatamento e favorecem a expansão da pecuária são conseqüentes da falta de utilização de insumos, acesso a créditos e outras fontes de capital, incluindo subsídios. Derivam, também, e, principalmente, da falta de conhecimento tecnológico do agricultor, das características do sistema fundiário e do mercado de terras, além das alterações macroeconômicas (PACHECO et al., 2005).

Com o advento das mudanças nas relações comerciais internacionais, que propiciou a abertura dos mercados, a atividade agropecuária, assim como os demais setores da economia nacional, a otimizar as suas unidades produtivas, a fim de tornarem-se mais competitivas. Nesse contexto, torna-se imperativo que a pecuária obtenha maior eficiência produtiva (MOURA CARVALHO et al., 2003).

O principal efeito indireto da estacionalidade climática na produção de ruminantes é com relação à quantidade e qualidade dos alimentos, determinado pelo ciclo produtivo das forragens. No período das chuvas, de modo geral, ocorre excesso de produção, o que proporciona abundância de forragem de boa qualidade e palatabilidade, além de favorecer o crescimento da planta. Por outro lado, durante o período de estiagem, as forragens têm a produção reduzida, tornando-se mais fibrosas, de reduzido valor nutritivo e baixa palatabilidade, bem como provocam oscilações no crescimento dos animais e aumento da idade de abate(VALENTIM \& MOREIRA, 1994; RESTLE et al., 1996).
Os solos de terra firme da Amazônia são de baixa fertilidade natural, consideravelmente incrementada pela incorporação de nutrientes, através das cinzas da biomassa vegetal, no processo inicial de formação da pastagem, o que propicia elevada produção de forragem, nos primeiros anos. O declínio da produtividade das pastagens está associado à redução da disponibilidade de nutrientes no solo, principalmente o fósforo, e ao seu manejo inadequado (LOURENÇO JÚNIOR et al., 2005). A pecuária tradicional extensiva permite ganho de peso vivo de $150 \mathrm{~kg}$.animal ${ }^{-1} \mathrm{ano}^{-1}$, com taxa de lotação conservadora

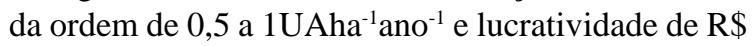
100,00. ha ${ }^{-1}$ ano $^{-1}$. Quando intensificada, essa rentabilidade pode quadruplicar, via fertilização e manejo das pastagens. O conhecimento da composição química, da digestibilidade e do consumo voluntário de determinado alimento permite adotar estratégia de manejo alimentar mais adequada às condições edafoclimáticas regionais.

Características da Pueraria phaseoloides (Roxb.) Benth Dentre os fatores limitantes à produção de carne e leite nas regiões tropicais, estão a baixa disponibilidade e qualidade das forragens, na época seca. Para solucionar esse problema, o produtor dispõe de algumas alternativas, nas quais se destaca o uso de leguminosas arbustivas como fonte de proteína para suplementação de animais manejados em pastagens formadas por gramíneas de reduzida qualidade nutricional. Existem leguminosas como a Leucena leucocephala e Gliricídia sepium que têm sido amplamente estudadas como fonte de alimentação para ruminantes.

A puerária (Pueraria phaseoloides) é uma leguminosa forrageira que ocupa posição de destaque na pecuária da região amazônica devido, em especial, às suas características agronômicas, tais como: adaptação aos solos ácidos e de baixa fertilidade e à sua agressividade, que the confere capacidade competitiva em relação às plantas invasoras (SOUZA FILHO et al., 2004). Essa espécie é relevante na produtividade das pastagens, pois incorpora $\mathrm{N}$ atmosférico aos sistemas solo-planta e melhora a alimentação do rebanho. Apresenta bom desempenho sob sombreamento, sendo utilizada como cultivo de cobertura do solo em plantações de seringueira e dendê, em toda a região (EMBRAPA, 1999).

Na escolha de uma leguminosa para a formação de bancos de proteína, devem-se considerar sua produtividade de forragem, composição química, palatabilidade, competitividade com as plantas invasoras, persistência, além da tolerância a pragas e 
doenças. Para as condições edafoclimáticas da região amazônica, as espécies normalmente recomendadas são amendoim-forrageiro (Arachis pintoi), guandu (Cajanus cajan), leucena (Leucaena leucocephala), puerária (Pueraria phaseoloides), centrosema (Centrosema macrocarpum), stylosantes (Stylosanthes guianensis) e calopogônio (Calopogonium mucunoides).

\section{Formas de estabelecimento}

Para ter sucesso garantido na formação de uma pastagem pura ou de banco de proteína da leguminosa, é necessário que a semeadura seja feita no início das chuvas. A área deve estar bem preparada (pelo método convencional: uma aração e duas gradagens) e livre de invasoras, já que a leguminosa apresenta desenvolvimento inicial bastante lento.

A semeadura da puerária deve ser feita em linhas de 0,5 a 1,0m de largura, à profundidade menor que $2,5 \mathrm{~cm}$. A semeadura em linhas visa facilitar as limpezas para controle das invasoras. Como as sementes apresentam o tegumento duro, recomendase sua escarificação antes da semeadura em linhas, devido à dormência mecânica. A escarificação pode ser feita por imersão em água quente $\left(80^{\circ} \mathrm{C}\right.$ por 3 a 5 minutos), em ácido sulfúrico concentrado por 20 minutos ou em solução de soda cáustica a $20 \%$ por 30 minutos (CAMARÃO et al., 1980; COSTA, 1990; COSTA, 2006). A semeadura deve ser realizada no início do período chuvoso (outubro/novembro). A densidade de semeadura deve ser de 3 a $4 \mathrm{~kg}$. ha-1 (lanço) e 2 a $3 \mathrm{~kg}$. $\mathrm{ha}^{-1}$ (linhas). Para a formação de pastagens consorciadas com gramíneas recomenda-se 0,5 a 1,5kg.ha ${ }^{-1}$ de sementes da leguminosa.

A semeadura pode ser feita manualmente ou utilizando-se implementos agrícolas disponíveis no comércio. Na Amazônia tem-se observado com freqüência em algumas leguminosas como a puerária, o desenvolvimento abundante de nodulações ativas, apresentando nódulos com coloração vermelha no seu interior. Entretanto, embora haja indicações de que a inoculação com bactérias do gênero Rizobium não é imprescindível, o potencial máximo de produção só é alcançado quando ela é inoculada (CANTARUTTI \& SILVA, 1990).

Recomenda-se para a semeadura em consorciação com gramíneas a densidade de 2 a $3 \mathrm{~kg}$ de sementes.ha-1 ${ }^{-1}$, sendo 6 a $8 \mathrm{~kg}$ de sementes.ha ${ }^{-1}$ a lanço e 2 a $3 \mathrm{~kg}$ de sementes.ha ${ }^{-1}$ em linhas (CAMARÃO et al., 1980; COSTA, 1990). Todavia, essa densidade depende do valor cultural das sementes.
Propagação

O preparo do solo, constitui através da aração e gradagem, o melhor recurso para o estabelecimento das leguminosas, além de facilitar as práticas de manutenção e manejo. No entanto, podese realizar a semeadura em áreas não-destocadas após a queima da vegetação. Os métodos de semeadura podem ser a lanço, em linhas ou em covas, manual ou mecânico (COSTA \& TOWNSEND, 2006). A puerária pode ser introduzida em pastagens degradadas, através dos métodos de plantio a lanço ou em sulcos, mantendo-se as densidades de semeadura entre 2,0 e $3,0 \mathrm{~kg} \cdot \mathrm{ha}^{-1}$, com valor cultural próximo a $64 \%$ (TOWNSEND \& COSTA, 1999).

\section{Produção de semente}

A produção de sementes viáveis é um dos principais mecanismos de sobrevivência de plantas em ambientes sujeitos a perturbações constantes, como é o caso das áreas de pastagens cultivadas da Amazônia brasileira. Para as leguminosas forrageiras, as sementes constituem-se importante veículo de suprimento de novos indivíduos para as áreas de pastagens. No entanto, ao serem liberadas pelas plantas para o ambiente, estão sujeitas a um conjunto de fatores ambientais relacionado às características do solo como o $\mathrm{pH}$, o nitrato e a salinidade, dentre outros, que exercem papel decisivo sobre a germinação das mesmas, com reflexos na população das plantas no campo (CARMONA, 1992; VILLIERS et al., 1994; CRUZ et al. 1995).

As sementes de puerária possuem habilidade para germinar em condições de meio onde o pH possa variar no intervalo 3 a 11. A salinidade afeta negativamente a germinação das sementes, sendo que até a concentração de $75 \mathrm{mM}$, as sementes germinam satisfatoriamente, sob o ponto de vista agronômico. O nitrato de potássio é um importante fator de solo a influenciar, positivamente, a germinação (velocidade e percentual) de sementes de puerária (SOUZA FILHO et al., 2004).

A maioria das leguminosas tropicais apresenta alta percentagem de sementes duras, ou seja, que não germinam logo após a semeadura. Em geral, a percentagem de sementes duras situa-se entre 60 e $90 \%$ e a dormência é devido à presença de cobertura impermeável à penetração da água, o que impede a germinação. Em condições naturais, a cobertura tornase gradualmente permeável e ocorre a germinação de certa proporção de sementes a cada período, o que contribui para assegurar a sobrevivência da espécie, principalmente, em regiões onde ocorrem secas prolongadas (SEIFFERT \& THIAGO, 1983; SEIFFERT, 1984). 
Valor nutritivo

A qualidade de uma forrageira é função de sua composição química, digestibilidade e consumo voluntário. O seu valor nutritivo depende da composição química, minerais, vitaminas, digestibilidade e natureza dos produtos digeridos. Contudo, a quantidade de forragem consumida pelos animais é muito importante. Vários são os fatores que afetam o consumo, tais como aceitabilidade pelo animal, presença de compostos anti-nutricionais nas forrageiras, taxa de passagem e disponibilidade de forragem. Portanto, a avaliação da qualidade de uma forrageira envolve integração do valor nutritivo e do consumo (DUTRA et al., 1997).

\section{Composição química}

Os teores médios de matéria seca (MS), proteína bruta (PB), fibra bruta (FB), fibra em detergente neutro (FDN), extrato etéreo (EE), extrativo nãonitrogenado (ENN), resíduo mineral fixo (RMF) e digestibilidade in vitro da matéria seca (DIVMS) de puerária foram 24,5\% (17,3 a 32,7\%), 17,9\% (9,20\% a $32,7 \%), 28,8 \%$ (26,1 a 42,9\%), 66,8\% (64,4 a 72,7\%), 2,2\% (1,9 a 3,0\%), 43,5\% (23,8 a 48,4\%), 7,3\% (6,0 a 10,3\%) е $52,8 \%$ (43,3 a 64,3\%), respectivamente(BOGDAN, 1977).

Os coeficientes de DIVMS, em média de $52,8 \%$, estão abaixo dos encontrados em folhas de germoplasmas, avaliados pelo Centro Internacional de Agricultura Tropical (CENTRO..., 1981) como Stylosanthes guianensis, S. hamata 147, respectivamente, 59,4 e 64,5\%. No entanto, são maiores que os de Desmodium ovalifolium e D. gyroides, respectivamente, de 40,1 e 36,5\%. A composição química da puerária, avaliada em banco de proteína, indica que a DIVMS, FDN, PB e proteína solúvel foram afetados pelo tempo e horários de acesso ao pastejo.

\section{Consumo e digestibilidade}

O consumo médio diário de matéria seca da puerária foi de 56,3 g de MS por Kg de peso metabólico (Kg0,75) (RUILOBA, 1990), enquanto Butterworth (1963) mencionou médias de digestibilidade "in vivo" da matéria seca, orgânica, PB, FB, EE e ENN, respectivamente, de 59,2\%, 67,7\%, 60,3\%, 51,9\% e $61,8 \%$.

Na época chuvosa, a relação folha/caule diminui com o aumento da idade. Segundo Minson (1977), o teor de PB da puerária não foi influenciado pela idade da planta, enquanto que os teores de PB das leguminosas diminuem lentamente com o avanço da idade. Praticamente não houve variação na energia bruta, teores de taninos e de FDN. O consumo de MS por ovinos foi superior, aos 5,5 meses de idade da planta, quando comparado ao período seco na mesma idade. Esse resultado contraria os obtidos com outras leguminosas, pois, quando a planta amadurece, aumentam os constituintes da parede celular e diminuem os nutrientes do conteúdo celular. Todavia, segundo o autor, esse resultado deve-se ao maior consumo de caule.

A digestibilidade da puerária, aos 3,5 meses, foi maior do que aos 5,5 meses, estando de acordo com os resultados obtidos em outras leguminosas. No verão (época seca), a relação folha/caule foi baixa, quando comparada com a do inverno. Isso demonstra que a puerária tem baixa capacidade de rebrotar e problemas de desfoliação ou perdas de folhas na época seca. Os teores de PB e de taninos foram maiores aos 3,5 meses no período seco do que no período chuvoso (MILFORD \& HAYDOCK, 1965; MINSON \& MILFORD, 1966).

A energia bruta foi semelhante e os teores de FDN foram maiores aos 5,5 meses. Comparando o valor nutritivo da puerária entre o inverno e verão, os teores de PB, taninos e os coeficientes de digestibilidade foram maiores no inverno e os de FDN foram maiores no verão. Todavia, o consumo foi maior no verão. Isto pode estar relacionado ao maior teor de taninos na forrageira no inverno (RUILOBA \& SALDANA, 1995).

Os taninos podem reduzir o consumo através do decréscimo da palatabilidade, devido à adstringência, que é uma sensação causada pela formação do complexo entre taninos e glicoproteínas da saliva e pode aumentar a salivação e diminuir a palatabilidade (REED, 1995). Todavia, a baixa palatabilidade de algumas espécies de plantas está relacionada ao teor de taninos de 5\% (McNAUGHTON, 1987). Em avaliação realizada pelo CIAT (CENTRO..., 1981), a puerária apresentou altos teores de PB (26,7\%), sendo que, aproximadamente, 32,5\% dessa proteína estão na fibra em detergente ácido. Essa proteína da parede celular está ligada à lignina, portanto não disponível aos microrganismos do rúmen, afetando o valor nutritivo da planta.

\section{Utilização da leguminosa por animais em pastejo}

No uso de puerária por ruminantes devem ser feitos ajustes no manejo, a fim de evitar sua agressividade, domínio da gramínea, principalmente, quando é de boa qualidade, o que reduz a quantidade de energia disponível (Figura 1). A lotação contínua pode aumentar sua proporção na pastagem, em regiões sem período seco definido. Informações sobre exigências nutricionais e inoculação com Rhizobium específico são raras na literatura, necessitando de pesquisas (ANDRADE \& KARIA, 2000). 


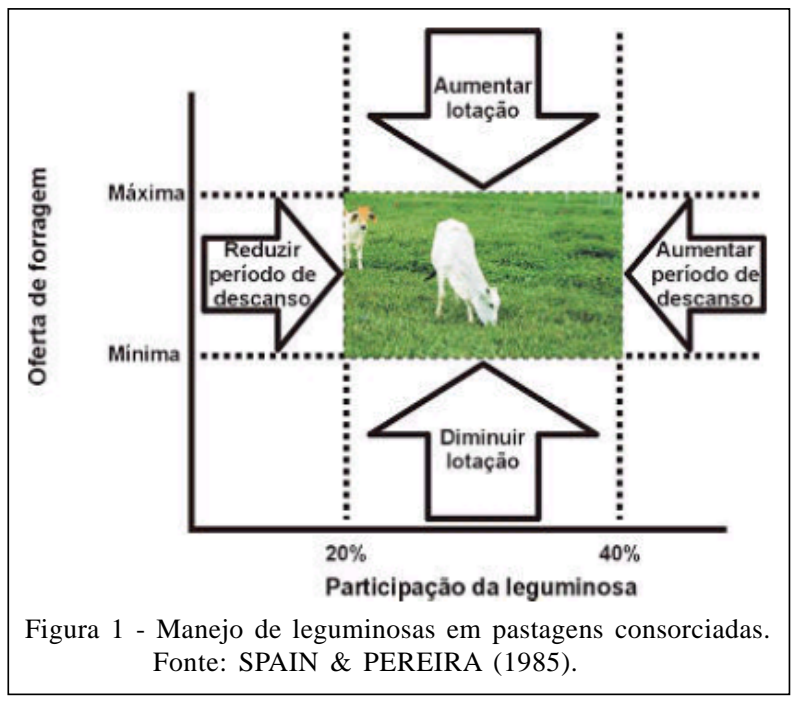

Em pastagens consorciadas, deve-se assegurar a estabilidade da leguminosa, componente mais valioso e instável da associação. Em Brachiaria humidicola, consorciada com puerária, a lotação animal não deve ser superior a 2,0UA. ha ${ }^{-1}$ e períodos de descanso não deve ultrapassar 28 dias. Dessa forma, além da manutenção da produtividade e persistência da pastagem, ter-se-á um balanço equilibrado gramínealeguminosa, mantendo-se proporção, em relação à disponibilidade de matéria seca verde total, entre 30 e 50\% para puerária (COSTA, 2006).

\section{CONCLUSÕES}

A suplementação alimentar de ruminantes, em períodos de estiagem, com a leguminosa puerária constitui excelente fonte de proteína e é considerada alternativa para elevar os índices zootécnicos dos sistemas de produção na Amazônia Oriental, devido ao estresse climático que a pecuária é submetida, com redução da disponibilidade e valor nutritivo das forrageiras, o que impede o atendimento as demandas nutricionais dos animais e causa danos à produtividade e competitividade do agronegócio.

Essa leguminosa pode ser estabelecida por sementes, de forma acessível a todos os produtores e pode ser utilizada em consorciação com gramíneas, em banco de proteína ou fornecida diretamente no cocho. Possui boas características de valor nutritivo e aceitabilidade pelos ruminantes, o que proporciona destacado consumo de matéria seca e eleva o padrão da dieta animal.

\section{AGRADECIMENTOS}

Ao Conselho Nacional de Desenvolvimento Científico e Tecnológico (CNPq), à Coordenação de
Aperfeiçoamento de Pessoal de Nível Superior (CAPES), pelas bolsas de estudo concedidas, e ao Banco da Amazônia S.A., através do Projeto Basa-Pecuária, pela ajuda financeira.

\section{REFERÊNCIAS}

ANDRADE, R.P.; KARIA, C.T. Uso de Stylosanthes em pastagens no Brasil. In: SIMPÓSIO DE FORRAGEIRAS E PASTAGENS, 2000, Lavras, MG. Anais... Lavras: UFLA/ NEFOR, 2000. p.273-310.

BOGDAN, A.V. Tropical pasture and fodder plants. London: Logman, 1977. 475p.

BUTTERWORTH, M.H. Digestibility trials on forages in Trinidad and their use in the prediction of nutritive value. Journal of Agriculture Science, v.60, n.3, p.77-81, 1963.

CAMARÃO, A.P. et al. Recuperação, melhoramento e manejo de pastagens na região de São João do Araguaia - Resultados e informações práticas. Belém: Embrapa Amazônia Oriental, 1980. 20p.

CANTARUTTI, R.B.; SILVA, S.D.V.M. Avaliação da efetividade de estirpes nativas de Rhizobium em diferentes condições de solo do sul da Bahia. In: REUNION DE LA RED INTERNACIONAL DE EVALUACION DE PASTOS TROPICALES - RIEP AMAZONIA, 1990, Lima, Peru. Anais... Lima: Centro Internacional de Agricultura Tropical, 1990. v.2, p.769-771.

CARMONA, R. Problemática e manejo de bancos de sementes de invasoras em solos agrícolas. Planta Daninha, v.10, n.1/2, p.5-16, 1992.

CASTRO, A.C. Avaliação de sistema silvipastoril através do desempenho produtivo de búfalos manejados nas condições climáticas de Belém, Pará. 2005. $75 f$. Dissertação (Mestrado em Ciência Animal) - Núcleo de Ciências Agrárias e Desenvolvimento Rural. Universidade Federal do Pará/Embrapa Amazônia Oriental/Universidade Federal Rural da Amazônia.

CENTRO INTERNACIONAL DE AGRICULTURA TROPICAL. Programa de pastos tropicales. Cali, 1981. 302p.

COSTA, N.L. Puerária: leguminosa forrageira para a produção de proteína. Porto Velho: UEPAE - Porto Velho, 1990. 4p. (UEPAE - Porto Velho, 92).

COSTA, N.L. Formação e manejo de pastagens de Puerária (Pueraria phaseoloides) na Amazônia Ocidental. Capturado em: 25 jan. 2006. Online. Disponível na internet: http://www.aviculturabrasil.com.br/Cietec/artigos/ ArtigosTexto.asp?Codigo $=548$

COSTA, N.L.; TOWNSEND, C.R. Utilização estratégica de pastagens durante o período seco na Amazônia Ocidental. Capturado em: 31 jan. 2006. Online. Disponível na internet: http://www.aviculturabrasil.com.br/Cietec/Artigos/ ArtigosTexto.asp?Codigo $=498$.

CRUZ, M.S.D. et al. Factos affecting germination of (Canavalia brasiliensis), (Leucaena leucocephala), (Clitoria ternata) and

Ciência Rural, v.39, n.2, mar-abr, 2009. 
(Calopogonium mucunoides). Seed Science Technology, v.23, n.2, p.447-454, 1995.

DUTRA, A.R. et al. Efeito dos níveis de fibra e das fontes de proteína sobre o consumo e digestão dos nutrientes em novilhos. Revista Brasileira de Zootecnia, v.26, n.4, p.787-796, 1997.

EMBRAPA. Redução dos impactos ambientais da pecuária de corte no Acre. Rio Branco: Centro de Pesquisa Agroflorestal do Acre, 1999. 2p.

LOURENÇO JÚNIOR, J.B. et al. Sistemas silvipastoris intensivos e manejo rotacionado da pastagem na produção de carne e leite de bovídeos na Amazônia. Belém: Federação da Agricultura do Estado do Pará - FAEPA, 2005. 12p.

McNAUGHTON, S.J. Adaptation of herbivores to season changes in nutrient supply. In: HACKER, J.B; TERNOUTH, J.H. Nutrition of herbivores. London: Academic, 1987. p.391-408.

MILFORD, R.; HAYDOCK, K.P. The nutritive value of protein in subtropical pasture species in south-east Queensland. Australian Journal Experimental Agricultural Animal Husbandry, v.5, p.13-20, 1965.

MINSON, D.J. Chemical composition and nutritive value of tropical of forages legumes. In: SKERMAN, P.J. Tropical forage legumes. Rome: FAO, 1977. p.186-195.

MINSON, D.J.; MILFORD, R. The energy values and nutritive value indexes of (Digitaria decumbens), (Sorghum almun) and (Phaseolus atropurpureus). Australian Journal Agricultural Research, v.17, p.411-423, 1966.

MOURA CARVALHO, L.O.D. et al. Produção intensiva de carne e leite à pasto - o "boi verde". Belém: Embrapa Amazônia Oriental, 2003. 7p.

PACHECO, P. et al. Pecuária, desenvolvimento regional e desmatamento na Amazônia Oriental. Belém: CIFOR, 2005. 2p. (EMBRAPA-CPATU. Documentos, 56).

REED, J.D. Nutritional toxicology of tannins and related plyphenols in forage legumes. Journal of Animal Science, v.75, p.1516-1528, 1995.

RESTLE, J. et al. Produção animal em pastagem nativa ou cultivadas durante o período de verão. In: REUNIÃO ANUAL DA SOCIEDADE BRASILEIRA DE ZOOTECNIA, 33, 1996,
Fortaleza, CE. Anais... Fortaleza: SBZ, 1996. v.1, p. 438-445.

RUILOBA, M.H. Banco de kudzu como fuente de proteína para a producción de leche en Panamá. Pasturas Tropicales, v.12, n.1, p.44-47, 1990.

RUILOBA, M.H.; SALDANA, C. Parametro quimicos y nutricionales del kudzu (Pueraria phaseoloides) cosechado en inverno y verano. Ciencia Agropecuaria, v.8, p. 69-83, 1995.

SEIFFERT, N.F. Leguminosas para pastagens no Brasil central. Brasília: EMBRAPA-DDT, 1984. 131p. (EMBRAPACNPGC. Documentos, 7).

SEIFFERT, N.F.; THIAGO, L.R.L.S. Legumineira: cultura forrageira para a produção de proteína. Campo Grande: EMBRAPA-CNPGC, $1983.52 p . \quad$ (EMBRAPA-CNPGC. Circular Técnica, 13).

SOUZA FILHO, A.P.S. et al. Germinação de sementes de Pueraria phaseoloides: efeitos do $\mathbf{p H}$, do nitrato e da salinidade. 2004. Capturado em: 29 jun. 2006. On line. Disponível em: www.sbz.org.br/eventos/PortoAlegre/ homepagesbz/For\%5CFOR193.htm.

SPAIN, J.M.; PEREIRA, J.M. Sistemas de manejo flexible para evaluar germoplasma bajo pastoreo: una propuesta. In: LASCANO, C.; PIZARRO, E. Evaliación de pastos com animales. Alternativas metodologias-RIEPT. Cali: CIAT, 1985. p.85-87.

TOWNSEND, C.R.; COSTA, N.L. Efeito do método de plantio e densidade de semeadura no estabelecimento de leguminosas tropicais em pastagens degradadas da Amazônia Ocidental. In: REUNIÃO ANUAL DA SOCIEDADE BRASILEIRA DE ZOOTECNIA, 36., 1999, Porto Alegre. Anais... Porto Alegre: SBZ, 1999. p.1-3.

VALENTIM, J.F.; MOREIRA, P. Adaptação, produtividade, composição morfológica e distribuição estacional da forragem de ecotipos de (Panicum maximum) no Acre. Rio Branco: EMBRAPA-CPAF/AC, 1994. 17p. (EMBRAPACPAF/AC. Boletim de Pesquisa, 11).

VILLIERS, A.J.J. et al. Germination of three nomaqualand pioneer species, as influenced by salinity, temperature and light. Seed Science Technology, v.22, n.3, p.427-433, 1994. 